\title{
Onychogryphosis: Case Report and Review of the Literature
}

\author{
Dayoung Ko ${ }^{a}$ Shari R. Lipner ${ }^{b}$ \\ ${ }^{a}$ Duke University School of Medicine, Durham, NC, USA; ${ }^{b}$ Department of Dermatology, Weill Cornell Medicine, \\ New York, NY, USA
}

\section{Established Facts}

- Onychogryphosis is a common nail condition seen in older individuals and patients with poor personal care.

- If left untreated, it may cause pain, paronychia, or onychocryptosis and is often a source of embarrassment.

\section{Novel Insights}

- Onychogryphosis may be managed conservatively by limiting pressure on the nail bed and using mechanical debridement.

- Definitive treatment for onychogryphosis is nail avulsion followed by matricectomy or surgical resection of the nail matrix.

\section{Keywords}

Nails · Onychogryphosis · Nail avulsion · Matricectomy · Phenolization yellow discoloration of his left great toenail, clinically consistent with onychogryphosis. This review highlights the etiology, diagnosis, and treatment options for onychogryphosis.

(c) 2018 S. Karger AG, Basel

\section{Introduction}

Onychogryphosis is a disorder of nail plate growth that is characterized by an opaque, yellow-brown thickening of the nail plate with associated gross hyperkeratosis, elongation, and increased curvature. It is often described as a "ram's horn nail" or being "oyster-like" in appearance. The nail plate initially grows upwards and thereafter deviates laterally towards the other toes $[1,2]$. According

\section{KARGER}

(C) 2018 S. Karger AG, Basel

E-Mail karger@karger.com

www.karger.com/sad
Shari R Lipner, MD, $\mathrm{PhD}$

E-Mail shl9032@med.cornell.edu 


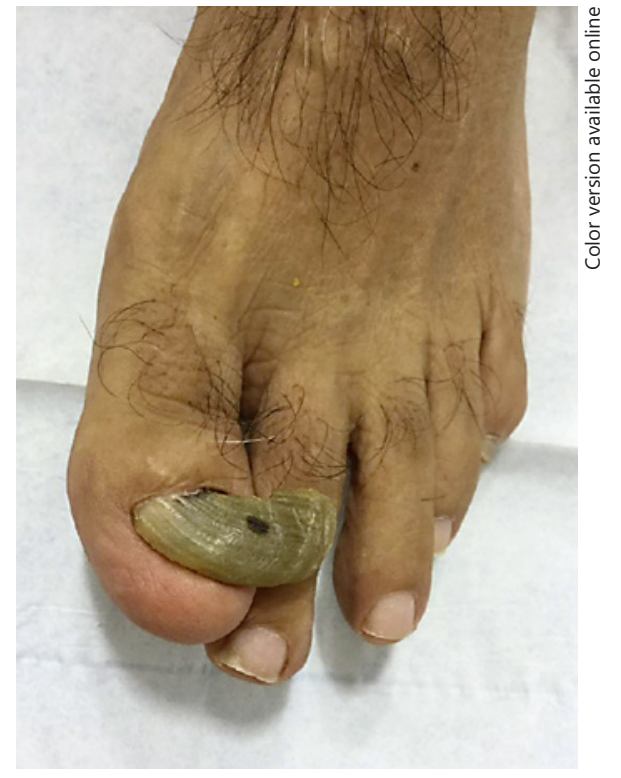

Fig. 1. Onychogryphosis of the left great toenail. Thickening and lateral deviation of the left first toenail, resembling a "ram's horn."

to Zaias [3], the nail plate grows hypertrophied and unevenly at the matrix, and the faster growing side is what determines the direction of the deformity. Two possible explanations for this deformity have been proposed: there may be insufficient nail matrix under the posterior fold to exert a flattening effect, or the nail bed may contribute a greater quantity of keratin to the nail than is normally seen [4]. The great toenail is most often affected, but the fingernail may be involved in rare cases. It is more commonly seen in elderly or homeless patients with signs of neglect [1].

\section{Case Report}

A 67-year-old man presented with a 30-year history of severe thickening, abnormal growth, and yellow discoloration of his left great toenail. He stated that the affected nail broke off midway every 6 months and then regrew. It had become more painful recently and was impinging on his second toe, making it difficult to walk and put on socks. There was no history of trauma, tinea pedis, or family history of onychomycosis. Physical examination was notable for thickening and lateral deviation of the left first toenail (Fig. 1). A nail clipping with histopathology was negative for fungal hyphae. An X-ray of the toe showed mild osteoarthritis, and there was no subungual exostosis. A diagnosis of onychogryphosis was made, and a nail avulsion with phenol matricectomy was performed as therapy.

Onychogryphosis

\section{Discussion}

\section{Prevalence}

The prevalence of onychogryphosis is highest in the elderly population. In one cross-sectional observational study on 173 patients in 3 nursing homes in Tokyo, the prevalence of onychogryphosis was $17.9 \%$ [5]. In another study conducted on 536 patients over the age of 75 years from 4 general practices, the reported prevalence was $11.2 \%$ [6]. In a hospital survey conducted on foot problems in 100 patients in 4 different wards, the reported prevalence was $38 \%$ [7].

\section{Causes}

\section{Congenital Onychogryphosis}

There are few reports of inherited cases of onychogryphosis. Congenital onychogryphosis has been described and inherited as an autosomal-dominant trait in which all the nails of both hands and feet may be involved. Onset is usually within the first year of life [8]. A case of congenital onychogryphosis was described in a 2-year-old girl who was born prematurely with anonychia. When all the nails grew, they were hypertrophic and deviated laterally [9]. Congenital onychogryphosis may clinically resemble and must be distinguished from congenital malalignment of the toenails and congenital pachyonychia $[10,11]$. Onychogryphosis is also a feature of Haim-Munk syndrome along with palmoplantar hyperkeratosis, severe early-onset periodontitis, pes planus, arachnodactyly, and acroosteolysis. Haim-Munk syndrome is an autosomal recessive genodermatosis caused by mutations in a lysosomal protease gene, cathepsin C [12]. Onychogryphosis has also been rarely reported to be associated with tuberous sclerosis, which may be due to poor nursing care, cognitive impairment, or subungual fibromas [13]. There have been reports of onychogryphosis as a feature of several congenital syndromes, including Papillon-Lefèvre syndrome [14], ichthyosis hystrix [15], and ectodermal dysplasia-syndactyly syndrome type I [16].

\section{Acquired Onychogryphosis}

Acquired onychogryphosis is most often observed in people with long-standing poor personal care or neglect, in homeless persons, and in people with senile dementia. Onychogryphosis may be associated with ichthyosis, psoriasis, pemphigus, syphilis, variola, and hyperuricemia [1, $17,18]$. Onychogryphosis is also seen with impairment of the peripheral circulation, including varicose veins, stasis dermatitis, and ulcers of the lower legs $[1,18,19]$. Onychogryphosis has been reported to be a result of an elastic 
wire for correction of a pincer nail [20]. Traumatic injuries to the nails, including burn injuries and microtrauma resulting in suppuration or scarring, may also result in onychogryphosis [4]. Microtrauma is often attributed to improperly fitting shoes or footgear, and foot anomalies, such as hallux valgus, may cause the nail to be more susceptible to trauma $[18,21]$. Table 1 summarizes causes of acquired onychogryphosis.

Interestingly, onychogryphosis and lym phadenopathy are present in $50-75 \%$ of dogs infected with leishmaniasis $[22,23]$. However, to date, there have been no reports of humans with leishmaniasis having onychogryphosis [24].

\section{Diagnosis}

Onychogryphosis remains largely a clinical diagnosis based on characteristic appearance. There is thickening of the nail plate with associated gross hyperkeratosis and increased curvature. The nail can be oyster-like or resemble a ram's horn, and its irregular surface is marked by longitudinal and transverse striations, the latter of which are more frequent. Diagnosis of onychogryphosis can be difficult to reach in the early stages because hypertrophy of the nail plate is the earliest manifestation, with the more classical features appearing later [1]. Histologically, there is a disorderly arrangement of keratinocytes within the nail plate with hyperchromatism, parakeratosis, and numerous splits [25]. The disorder may be confused clinically with onychomycosis, and fungal studies can be used to rule out the latter. It should be noted, however, that onychomycosis and onychogryphosis can coexist.

Hemi-onychogryphosis is a condition mimicking onychogryphosis in which the nail plate grows laterally from birth or early childhood. This may be a complication of persistent congenital malalignment of the great toenails. It can be prevented by regular nail plate trimming and foot care [2].

\section{Complications}

Some common complications of onychogryphosis include ingrown toenails, paronychia, secondary onychomycosis, and the inability to cut the toenail due to increasing hypertrophy of the nail plate [21]. Rarely, the lateral part of the proximal nail fold may become indurated [26]. Infrequently, subungual gangrene may ensue [2].

\section{Management and Treatment}

Treatment is warranted to prevent complications and for cosmesis [2] (Table 2). Therapy depends on the cause and patient comorbidities; onychogryphosis can be treated palliatively or operatively [21]. Initially, every effort
Table 1. Causes of acquired onychogryphosis

\begin{tabular}{ll}
\hline Causes of acquired onychogryphosis \\
\hline Poor self-care & $\begin{array}{l}\text { Advancing age } \\
\text { Homelessness } \\
\text { Senile dementia }\end{array}$ \\
\hline Dermatologic diseases & Ichthyosis \\
& Pemphigus \\
& Psoriasis \\
\hline Infectious diseases & Onychomycosis \\
& Syphilis \\
& Variola \\
\hline Local causes & Major trauma to the nail \\
& Microtrauma caused by footwear \\
& Foot anomalies (e.g., hallux valgus) \\
& Nail surgery \\
\hline Medical disorders & Varicose veins \\
& Thrombophlebitis \\
& Ulcers of the lower leg \\
& Hyperuricemia \\
\hline & \\
\hline & \\
&
\end{tabular}

should be made to avoid excessive pressure on the nail bed. Footwear should be reviewed to assess appropriate fit, avoiding excessive pressure or microtrauma to the toes [25]. Conservative methods are preferred in the elderly population, particularly in patients with vascular impairment or hyperglycemia due to diabetes. In the majority of these cases, regular use of electric drills, burs, or mechanical debridement with a dual-action nail nipper (Fig. 2) will help establish and maintain a reduction of nail plate thickness and length $[27,28]$. Using cryotherapy on the nails before nail trimming makes it easier to cut the nail with an even edge [29].

In patients with good vascular supply, a nail avulsion or removal of the thickened nail plate may be indicated. A blunt dissection using a regular nail clipper can be used after chemical avulsion with $40 \%$ urea or $50 \%$ potassium iodine under occlusion. Onychogryphosis invariably recurs after a simple nail avulsion [30]. In 1 study, a simple nail avulsion was performed on 29 onychogryphosis patients who had failed conservative treatment. The recurrence rate after 12 months was $93 \%$; however, only $17 \%$ were symptomatic [31].

If conservative methods fail and the patient is symptomatic, the definitive treatment is nail avulsion followed by matricectomy. In 1 study conducted on 96 patients with recurrent onychogryphosis, the authors reported a significant advantage of the nail avulsion with matricec- 
Table 2. Treatment options for onychogryphosis

\begin{tabular}{ll}
\hline Therapy & Methods \\
\hline Conservative treatment (nonsurgical) & $\begin{array}{l}\text { Dual-action nail nippers, mechanical burs, and drills for } \\
\text { mechanical debridement of the nail }\end{array}$ \\
\hline Simple nail avulsion without matricectomy & Blunt dissection after chemical avulsion \\
\hline Nail avulsion with matricectomy & $\begin{array}{l}\text { Chemical ablation (phenolization) } \\
\text { Cold steel } \\
\text { Zadik procedure } \\
\text { Electrosurgery } \\
\text { CO laser }\end{array}$ \\
\hline $\begin{array}{l}\text { Nail avulsion with matricectomy with V-Y } \\
\text { advancement flap }\end{array}$ & $\begin{array}{l}\text { Triangular flap designed with the apex at the distal } \\
\text { interphalangeal crease and the base at the edge of the lesion }\end{array}$ \\
\hline Syme method & $\begin{array}{l}\text { One-half of the terminal phalanx is excised together with the } \\
\text { nail fold }\end{array}$ \\
\hline
\end{tabular}

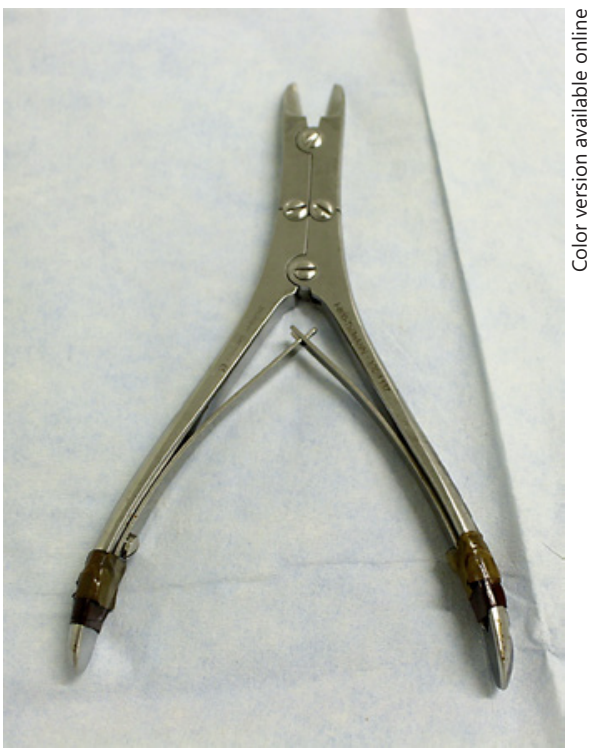

Fig. 2. Dual-action nail clippers. This device can be used for diagnostic and therapeutic purposes for onychogryphosis.

tomy compared to a simple nail avulsion alone [32]. Matricectomy can be achieved either by excision or ablation [33]. Excisional techniques include cold steel, cutting electrosurgery, or a laser used in the cutting mode. Ablative techniques include chemocautery, electrocautery, or a laser in the ablative mode [33].

In some cases, surgical resection of the entire nail matrix is indicated. Using local anesthesia and tourniquet control and the Zadik technique, 2 oblique 0.5 -inch incisions are made, beginning at the junction of the nail fold and nail walls, extending laterally and proximally [34]. Sharp dissection is used to avulse the nail and remove the germinal matrix and the overlying deep layer of the nail fold and walls. The skin flaps are sutured back to cover the wound [30]. This technique can also be modified to be a partial matricectomy, in which an entire wedge of nail matrix is excised [33]. Another surgical technique utilizes a matricectomy with a V-Y advancement flap, which is a triangular flap designed with the apex at the distal interphalangeal crease and the base at the edge of the lesion. The advantages of the V-Y advancement flap are preservation of sensation and length and good softtissue coverage [35]. The most radical technique, rarely used today, is the Syme method, in which one-half of the terminal phalanx is also excised together with the nail fold [36].

Ablation of the nail matrix can be performed with electrodessication. Advantages of this method are minimal postoperative pain and drainage and that it can be performed quickly. Ablation may also be performed by chemocauterization with phenol (supersaturated solution, $88 \%$ ) or with $10 \%$ sodium hydroxide with excellent success rates $[9,37]$. In a study of 107 patients with onychogryphosis or ingrown toenails, phenol cauterization was superior to Zadik procedure for both nail conditions. Phenol cauterization resulted in fewer recurrences of nail spikes as well as fewer cases requiring further surgical treatment [37]. The carbon dioxide $\left(\mathrm{CO}_{2}\right)$ laser is also used to treat onychogryphosis [38]. Advantages of this technique in- 
clude more selective destruction of the matrix epithelium without causing necrosis of adjacent dermal tissue, less postoperative pain, and shortened healing time [38]. method for the treatment of onychogryphosis, while minimizing adverse effects.

\section{Statement of Ethics}

The patient's consent has been obtained for the publication of Figure 1 . close.

\section{Disclosure Statement}

Dayoung Ko and Dr. Lipner have no conflicts of interest to dis-

can be managed conservatively or surgically. Further studies are needed to evaluate the most beneficial surgical

recognize and treat due to pain and sequelae, including onychocryptosis and paronychia, and for cosmesis. Depending on the patient's comorbidities, onychogryphosis

\section{References}

$>1$ Chang P, Meaux T: Onychogryphosis: a report of ten cases. Skinmed 2015;13:355-359.

-2 Singh G, Haneef NS, Uday A: Nail changes and disorders among the elderly. Indian J Dermatol Venereol Leprol 2005;71:386-392.

3 Zaias N: The Nail in Health and Disease. Springer Science \& Business Media, 2012.

4 Oka H, Asakage Y, Inagawa K, Moriguchi T, Hamasaki T: Free vascularized nail grafts for onychogryphosis of bilateral thumbnails after burn injury. Burns 2002;28:273-275.

5 Nakagami G, Takehara K, Kanazawa T, Miura Y, Nakamura T, Kawashima M, Tsunemi $\mathrm{Y}$, Sanada H: The prevalence of skin eruptions and mycoses of the buttocks and feet in aged care facility residents: a cross-sectional study. Arch Gerontol Geriatr 2014;58:201-204.

6 Barlow AM, Braid SJ, Jayson MI: Foot problems in the elderly. Clin Rehabil 1990;4:217222.

$>7$ Ebrahim SB, Sainsbury R, Watson S: Foot problems of the elderly: a hospital survey. $\mathrm{Br}$ Med J (Clin Res Ed) 1981;283:949-950.

8 Baran R, de Berker DA, Holzberg M, Thomas L (eds): Baran and Dawber's Diseases of the Nails and Their Management. John Wiley \& Sons, 2012.

$>9$ Sequeira JH: Case of congenital onychogryphosis. Proc R Soc Med 1923;16(Dermatol Sect):92.

$>10$ Nath AK, Udayashankar C: Congenital onychogryphosis: Leaning Tower nail. Dermatol Online J 2011;17:9.

$>11$ Lipner SR, Scher RK: Congenital malalignment of the great toenails with acute paronychia. Pediatr Dermatol 2016;33:e288-e289.

$\checkmark 12$ Pahwa P, Lamba AK, Faraz F, Tandon S: Haim-Munk syndrome. J Indian Soc Periodontol 2010;14:201-203.

13 Han XC, Zheng LQ, Zheng TG: Onychogryphosis in tuberous sclerosis complex: an unusual feature. An Bras Dermatol 2016;91: 116-118.
14 Hattab FN, Amin WM: Papillon-Lefèvre syndrome with albinism: a review of the literature and report of 2 brothers. Oral Surg Oral Med Oral Pathol Oral Radiol Endod 2005;100: 709-716.

$>15$ Biswas P, Abhishek D, Sendur S, Nag F, Saha A, Chatterjee G: A case of ichthyosis hystrix: unusual manifestation of this rare disease. Indian J Dermatol 2014;59:82-84.

16 Mohammad A: Unusual manifestations of ectodermal dysplasia-syndactyly syndrome type I in two Yemeni siblings. Dermatol Online J 2015;21.

17 Freiberg A, Dougherty S: A review of management of ingrown toenails and onychogryphosis. Can Fam Physician 1988;34:2675-2681.

18 Müller C: On the causes of congenital onychogryphosis. Münch Med Wochenschr 1904;49:2180-2182.

19 Barkhordari K, Shafiee A: Ram's horn nail in lower-limb ischemia. J Tehran Heart Cent 2015;10:163-164.

20 Harada K, Yamaguchi M, Watanabe S, Shimada S: Onychogryphosis by an elastic wire. J Dermatol 2013;40:1055-1056.

21 Kouskoukis CE, Scher RK: Onychogryphosis. J Dermatol Surg Oncol 1982;8:138-140.

22 Ferreira MG, Fattori KR, Souza F, Lima VM: Potential role for dog fleas in the cycle of Leishmania spp. Vet Parasitol 2009;165:150154.

23 Alvar J, Canavate C, Molina R, Moreno J, Nieto J: Canine leishmaniasis. Adv Parasitol 2004;57:1-88.

24 Moreno J, Alvar J: Canine leishmaniasis: epidemiological risk and the experimental model. Trends Parasitol 2002;18:399-405.

25 Mc Dermott R, Kidney R: Celtic tiger: a case of onychogryphosis. Int $\mathrm{J}$ Case Rep Imag 2012;3:27-29.

26 Wagner G, Sachse MM: Congenital malalignment of the big toe nail. J Dtsch Dermatol Ges 2012;10:326-330.
27 Chelidze K, Lipner SR: In the toolbox: the dual action nail clipper. Dermatol Surg 2017, Epub ahead of print.

28 Möhrenschlager M, Wicke-Wittenius K, Brockow K, Bruckbauer H, Ring J: Onychogryphosis in elderly persons: an indicator of long-standing poor nursing care? Report of one case and review of the literature. Cutis 2001;68:233-235.

-29 Yang TH, Tsai HH: Performing cryotherapy on onychogryphotic nails before nail trimming. J Am Acad Dermatol 2016;75:e69-e70.

$\checkmark 30$ Fowler AW: Excision of the germinal matrix: a unified treatment for embedded toe-nail and onychogryphosis. Br J Surg 1958;45:382387.

-31 Greig JD, Anderson JH, Ireland AJ, Anderson JR: Simple avulsion of onychogryphotic toenails: a justifiable treatment? Postgrad Med J 1989;65:741-742.

32 Zhang H, Deng Q: The application of the germinal matrix, nail bed and nail plate ablation to cure the relapse onychogryphosis. Xinjiang Yi Xue Yuan 2010;6:034.

$\checkmark 33$ Ceilley RI, Collison DW: Matricectomy. J Dermatol Surg Oncol 1992;18:728-734.

34 Zadik FR: Obliteration of the nail bed of the great toe without shortening the terminal phalanx. Bone Joint J 1950;32:66-67.

35 Gürbüz K, Ozan F, Kayali C, Altay T: Total matricectomy and VY advancement flap technique in the treatment of onychogryphosis. Dermatol Surg 2017;43:583-586.

36 Townsend AC, Scott PJ: Ingrowing toenail and onychogryphosis. Bone Joint J 1966;48: 354-358.

37 Andrew T, Wallace WA: Nail bed ablation excise or cauterise? A controlled study. $\mathrm{Br}$ Med J 1979; 1:1539.

>38 Kaplan I, Labandter H: Onychogryphosis treated with the $\mathrm{CO}_{2}$ surgical laser. Br J Plast Surg 1976;29:102-103. 